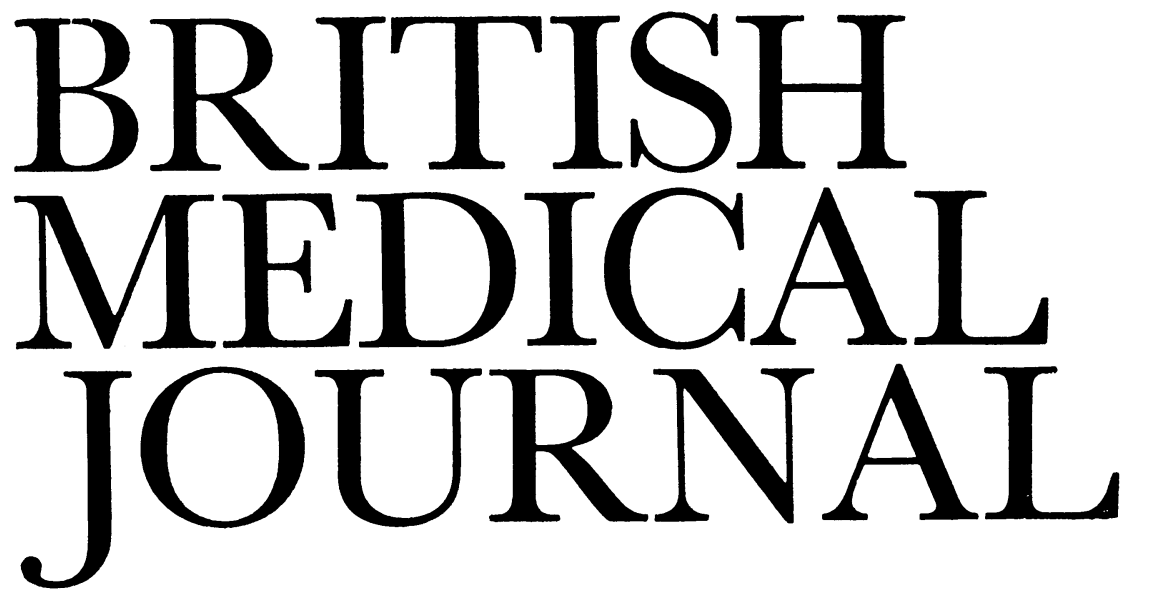

\title{
What price psychotherapy?
}

"An undefined technique applied to unspecified cases with unpredictable results. For this technique rigorous training is required." How much the uncomfortable truth embedded in this old, caustic definition of psychotherapy continues to raise professional hackles is well shown by the reactions to a "metaanalytic" assessment of published psychotherapeutic versus placebo studies published recently in The Behavioral and Brain Sciences, a journal which carries open peer commentary. ${ }^{1}$

The conclusion by Prioleau et al ${ }^{1}$-that "the benefits of psychotherapy do not exceed those of placebo in real patients" - provoked a predictably sharp division of opinion among the 23 commentators. For some, the findings confirmed the non-specific nature of psychotherapy in most of its various guises; for others, they merely indicated the need for more and better investigations. One of the most thoughtful responses was that of the much respected Jerome Frank, whose conclusions reflect long research experience in the subject: "With many patients the placebo may be as effective as psychotherapy because the placebo condition contains the necessary, and possibly the sufficient, ingredient for much of the beneficial effect of all forms of psychotherapy. This is a helping person who listens to the patient's complaints and offers a procedure to relieve them, thereby inspiring the patient's hopes and combating demoralisation."2

So bland a conclusion borders on the self evident. Why, then, should another influential commentator, Brendan Maher, observe that Prioleau et al "must expect to be attacked with a vigour that will be relatively independent of the rationality of their conclusions" ?3 In the United States the immediate reasons have to do more with economics and medical politics than with the niceties of scientific inquiry. Psychotherapy there is big business, and its exponents are mostly in private practice, where their income depends largely on third party payments from medical insurance. As Maher points out, this state of affairs has already resulted in widespread lobbying for the inclusion of mental disorder in insurance policies and in extensive advertising through the mass media. In addition, because the practice of psychotherapy remains without firm professional credentials, understandable but unseemly competition has developed between rival groups of mental health professionals-psychiatrists, psychologists, social workers, nurses, and counsellors of various persuasion. ${ }^{4}$ And, since the recent move towards making federal funds for psychotherapy dependent on proof of efficacy and safety, ${ }^{5}$ the suggestion that a psychotherapist is little more than a placebologist must be, in Maher's pithy phrase, "as welcome as a tax auditor at a business lunch."

The implications of this vigorous transatlantic debate for the National Health Service have been apparent for some time. ${ }^{6}$ Some of them may be detected in discussions of the registration of psychotherapists ${ }^{78}$ and of the justification for recognising so amorphous an activity as a specialised form of medical practice within the structure of a publicly financed health service. ${ }^{9}$ It is pertinent to recall a central point made by Sir John Foster in his report on scientology, ${ }^{10}$ a form of psychotherapy to its founder, a brand of quackery in the eyes of many, and a religion according to the High Court of Australia. As Foster pointed out: "those who feel they need psychotherapy tend to be the weak, the insecure, the nervous, the lonely, the inadequate, and the depressed." With so large and vulnerable a section of the population seeking help it is hardly surprising that nostrums are offered by an increasing number of thaumaturgical, pastoral, and blatantly commercial systems laying claim in one way or another to be "psychotherapeutic."

Here may be the key to an understanding of why the heat generated by psychotherapeutic polemics cannot be attributed to professional, technical, legal, or financial considerations alone. In his massive historical and clinical study of psychological healing Pierre Janet included miracles, philosophy, moral guidance, hypnotism, suggestion, rest, isolation, "mental liquidation" (a term which includes psychoanalysis), education, excitation, magnetism, and psychophysiological methods within the orbit of psychotherapeutics. ${ }^{11}$ As Janet makes clear, when stripped of their pseudoscientific pretensions all forms of psychotherapeutic activity are responses to a widespread demand for reassurance, hope, and support, accompanied by a willingness to believe in what is being offered for the purpose. In short, they are responses to part of the human condition.

The doctor's dilemma was clearly identified by Daniel Tuke in his observations on the influence of mind on the body 100 years ago: "scepticism in the physician is the best means of arriving at the truth: faith in the patient the best means of arriving at health." 12 In theory the double blind, placebo controlled clinical trial goes some way towards resolving this conflict, but in practice, and despite much evidence, ${ }^{13} 14$ the function of the placebo in medical therapeutics tends to be minimised: Goodman and Gilman, for example, devote three short paragraphs out of 1700 pages to placebo effects, concluding that, "Although the inert medication may be an 
effective vehicle for a placebo effect, the physician-patient relationship is generally preferable." 15 But if, as Prioleau et al maintain, the relationship is itself a form of placebo-if the medium constitutes the message-then the problems of evaluation become more complex. Several of the difficulties emerged from an ill fated Medical Research Council trial some 10 years ago, ${ }^{16}$ though other studies have since shown that at least some of the obstacles can be overcome. ${ }^{17}$ Unfortunately, most of the major research bodies in Britain appear to fight shy of the topic, and the professional organisations, including the Royal College of Psychiatrists, have done little more than pay lip service to the need for action. With its broader view of hygiene and its professed concern for the consumer, perhaps the new College of Health might be prepared to confront the issues more directly?

MichaEl Shepherd

Professor of Epidemiological Psychiatry,

Institute of Psychiatry,

London SE5 8AF

1 Prioleau L, Murdoch M, Brody B. An analysis of psychotherapy versus placebo studies. The Behavioral and Brain Sciences 1983;6:275-85.

${ }^{2}$ Frank JD. The placebo is psychotherapy. The Behavioral and Brain Sciences 1983;6:291-2.

${ }^{3}$ Maher B. Meta-analysis: we need better analysis. The Behavioral and Brain Sciences 1983;6:297-8.

4 McGuire TG. Markets for psychotherapy. In: Vandenbos GR, ed. Psychotherapy: practice, research, policy. Beverly Hills: Sage Publications, $1980: 187-245$.

${ }^{5}$ London P, Klerman GL. Evaluating psychotherapy. Am $\mathcal{f}$ Psychiatry 1982;139:709-17.

${ }^{6}$ Shepherd M. Psychoanalysis, psychotherapy, and health services. Br Med $\mathcal{f}$ 1979 ;ii:1557-9.

${ }^{7}$ Shepherd M. The statutory registration of psychotherapists? Bulletin of the Royal College of Psychiatrists 1980;4:166-8.

${ }^{8}$ Report of Psychotherapy Section Executive Committee. Statutory registration of psychotherapists. Bulletin of the Royal College of Psychiatrists 1983;7:190-5.

9 Wilkinson G. Psychotherapy in the marketplace. Psychol Med (in press).

${ }^{10}$ Foster JG. Enquiry into the practice and effects of scientology. London: HMSO, 1971

11 Janet P. Les médications psychologiques. 3 vols. Paris: Alcan, 1919.

12 Tuke DH. Illustrations of the influence of the mind upon the body in health and disease. 2nd ed. London: J \& A Churchill, 1884:287.

13 Jospe $M$. The placebo effect in healing. Lexington, Mass: Heath and Co, 1978.

${ }^{14}$ Lindahl O, Lindwall L. Is all therapy just a placebo effect? Metamedicine $1982 ; 3: 255-9$.

${ }^{15}$ Gilman AG, Goodman LS, Gilman A, eds. The pharmacological basis of therapeutics. 6th ed. New York: Macmillan, 1980.

${ }^{16}$ Candy J, Balfour FHG, Cawley RH, et al. A feasibility study for a controlled trial of formal psychotherapy. Psychol Med 1972;2:345-62.

17 Sloane RB, Staples FR, Cristol AH, Yorkston NJ, Whipple K. Psychotherapy versus behavior therapy. Cambridge, Mass: Harvard University Press, 1075.

\section{Pharmacy: an inquiry into its contribution to patient care}

Medicine and pharmacy have common roots, and their responsibilities remain complementary, the patient depending on the pharmacist to supply the medication prescribed by his doctor. Despite some minor feuds (such as those associated with dispensing doctors in rural areas), major changes in either profession must inevitably have important consequences for the other; certainly both will want to examine the proceedings and conclusions of the recently announced Nuffield Foundation Pharmacy Inquiry.

The status of pharmacists in hospitals has improved considerably during the past decade-since the Noel Hall report $^{1}$ and the subsequent reorganisation of the Health Service. Clinical pharmacy has not developed in Britain in the same mould as in some centres in the United States, but nevertheless ward pharmacy has been established in many hospitals, pharmacists are often included in the membership of drugs and therapeutics committees, and the hospital pharmacy is often the source of local drug information-for general practitioners as well as hospital staff.

Whereas only 3700 pharmacists work in hospitals, about 18000 are in community (retail) pharmacy, which seems likely to receive most of the attention of the committee of inquiry. In recent years the retail pharmacist has abandoned his measuring of quantities of liquid medicines, counting of tablets into bottles, or even preparing galenical formulations himself; instead, he now usually dispenses drugs prepared and packaged by their manufacturers. Furthermore, though most non-prescription drugs are available only from a pharmacy, some common symptomatic remedies such as aspirin and paracetamol may be bought in supermarkets without the supervision for which the pharmacist has always sought and accepted responsibility.

Retail pharmacy has predictably responded to these changes in several ways. Most pharmacists have diversified into other retail lines, some remote from health care. A few have attempted to present a more responsible and specialised image, restricting their activities entirely to drug dispensing and setting up patient record systems comparable with those of their medical practitioner colleagues. Which way is retail pharmacy to go? The answer is crucial for the future of pharmacy education.

Many pharmacists believe very strongly that "a pharmacist is indeed the leading authority on drugs and medicines, their chemistry, and their pharmacology."2 One has even composed a mantra to be "muttered" every morning: "I am the person who knows all about medicines, and I am not giving way to anyone else on that subject." Such an attitude ignores the inseparable relation between a medicine and the disease it was designed to treat. Present education in pharmacy does not equip its graduates with an adequate basic understanding of pathology and therapeutics. Certainly several postgraduate diploma and master's courses in clinical pharmacy are now available which provide such teaching to relatively few, and larger numbers of pharmacists attend less formalised introductory courses to clinical medicine, but the clinical content of the undergraduate schools of pharmacy (some of them in universities, others in polytechnics) is very variable. Few schools of pharmacy include experience of contact with the patient-customer in their undergraduate practical courses. My own experience suggests that clinical concepts and terminology are better understood by the pharmacy graduates of some polytechnic departments than by those from well known university departments, whose academic research interests may be remote from the therapeutic use of medicines in sick patients.

Clearly the pharmaceutical profession wants to be more intimately and responsibly concerned in the care of patients. Doctors must not ignore or shrug off this desire. Many pharmacists entered their profession because they saw it as an alternative to medicine when their attempts to enter medical schools were unsuccessful. The Pharmaceutical Society of Great Britain has recently been looking closely at what the response of the retail pharmacist should be to the patient's symptoms. A College of Pharmacy Practice has been set up to scrutinise and supervise postgraduate professional 